\title{
Elevating Professional Reasoning in Auditing. Psycho-Professional Factors Affecting Auditor's Professional Judgement and Skepticism
}

\author{
Delia DELIU \\ Faculty of Economics and Business Administration \\ West University of Timişoara, Timişoara, Romania, \\ delia.deliu@e-uvt.ro
}

Received date:4 October 2019; Accepted date:14 December 2019; Published date: 5 June 2020

Academic Editor: Cristina-Nicoleta Caranica

Copyright (C) 2020. Delia DELIU. Distributed under Creative Commons Attribution 4.0 International CC-BY 4.0

\begin{abstract}
The behaviour, as well as the professional conduct, both corroborated with the implications of the decisions taken by each professional in the field in which he carries out his activity, has represented the subject of researches in many disciplines, such as: psychology, medicine, economics and law. This aspect leads to the fact that the exercise of professional judgment is a process indispensable to each field of activity. In this regard, and especially in the context of this paper, it is important to specify that the assessment of the professional judgment's quality and correctness is a difficult issue, especially for the situation in which, professionals'opinions may be different. The issue of professional judgment and decision-making process has an interdisciplinary character, being treated in areas such as: psychology, medicine, law, accounting, etc. The interdisciplinary approach of this process gives it a high degree of complexity. Facts also revealed, by the large number of researches in the specialty literature, the diversity of factors that compete in the foundation of the professional judgment and decision-making process. Auditors' role and responsibilities is a controversial topic that has generated, in recent years, many discussions among specialists in the field. With the economic changes caused by the global crisis that "poisoned" the entire world, the risks to which auditors are subject to have grown and diversified considerably. This paper explored the ways in which the audit mission's efficiency is given by a theoretical and practical approach of the whole process. Therefore, this paper aims to present a model able to depict the picture of the main psycho-professional traits that characterize the behaviour involved in exercising this process of professional judgment. The paper adopted a descriptive methodology in outlining the influence of psychological traits for an effective reasoning. Precisely, it tested the causal processes by which certain abilities and traits of the auditor influence the quality of the audit mission. The findings of this paper point out the fact that in addition to the theoretical knowledge related to a professional training, it is necessary that the auditor, who carries on his activity, has sufficient experience, communication and teamwork skills, the ability to distinguishe the important and relevant elements for the fulfilment of his duties, and the responsibility regarding his tasks. The conclusion was reached that the manifestation of a skeptical and objective attitude contributes to the exercise of control over the decisions taken and the results obtained. Moreover, the combination of professional qualities and competences with psychological ones aims to provide correct, clear and compelling solutions for beneficiaries of the audit report. The paper proposes that further research efforts could empirically assess the extent to which psychological elements can influence auditors' professional judgment in diverse cultures.
\end{abstract}

Keywords: Professional Judgment, Professional Reasoning, Skepticism, Financial Audit, Audit Opinion

JEL Classification: M21, M42, D91

Cite this Article as: Delia DELIU (2020),"Elevating Professional Reasoning in Auditing. PsychoProfessional Factors Affecting Auditor's Professional Judgement and Skepticism", Journal of Accounting and Auditing: Research \& Practice, Vol. 2020 (2020), Article ID 804680, DOI: 10.5171/2020.804680 


\section{Introduction}

"Good judgment comes from experience. Experience comes from bad judgment" (according to Jim Horning, after the wellknown character Mulla Nasruddin in the 16 th century Sufi Sage novel, unknown author). This avowal highlights that reasoning or judgment can only be learned, acquired or enhanced through a "school of own failures", based on rich experience. Also, Oscar Wilde, an illustrious Irish poet, novelist and critic, alleged that "experience is simply the name we give our mistakes".

Therefore, if in the exercising of the different professions, the professionals did not make mistakes, they would not be able to differentiate the right decisions from the wrong ones and they would not have the ability to avoid those circumstances that previously led to the wrong choices. Learning from mistakes is a way to reach highest performance more easily. For this, however, it is necessary to be aware of ones' mistakes, understand the circumstances that led to their occurance and consequently, identify methods to avoid them in forthcoming activities.

An aspect worth mentioning is found in the statement of the English logician and philosopher Bertrand Russell, according to which, "thinking you know when in fact you don't is a fatal mistake, to which we are all prone".

Thus, it is considered necessary for professionals to be conscious of the limits that may interfere in the conduct of their activities. In the event that personal knowledge, experience or skills are not sufficient to complete the mission, it is advisable to consult other specialists. It is preferable to resort to a specialized support for decision-making rather than opting for individual reasoning that will later lead to mistakes that are difficult to correct. The professional reasoning allows the awareness and knowledge of what is not known and also the decision-making regardless of the limits of the circumstances.

As a starting point in understanding the concept of professional reasoning, the author of this paper notices two elements of the etymological nature from which it is composed. In this sense, "judgment" defines a profession, in fact, the ability to exercise adequate or higher quality reasoning, designating something essential to the success of any profession, as Roy (2011) points out. According to the information provided in Webster's Dictionary, the term reasoning was first used in the thirteenth century and refers to: "a formal statement of an approved opinion; the process of forming an opinion or evaluation through discernment or comparison; the ability to judge; discernment". As for the term "professional", on the other hand, it was used much later, in the early '60s, being derived from the term "profession", namely the call for which specialized knowledge and intensive training are required in a field, a vocation or an engagement. Thus, with regard to the term "professional" as a part of the concept of "professional reasoning", it may have the following meanings: referring to a specific characteristic of a profession, engaged in one of the acquired professions and characterized or in accordance with the technical or ethical standards of a profession; which presents a polite and conscientious way of people at work.

Professional judgment/reasoning is often confused with decision. Researches in the field noted a dissimilarity between these two concepts, which is not infrequent, however, it is quite difficult to highlight. Hence, Bonner (1999) explains: "the term of reasoning refers to the formation of an idea, an opinion or an estimation regarding the object, the success, the state or another type of phenomenon". According to Perez (2001), however, reasoning and decisions are similar; the stages of the two processes are almost identical from the cognitive perspective.

However, in this study's opinion, judgment takes the form of a future forecast or an assessment of the current state of affairs, while decision, on the other hand, involves the realization of a theme, on a mental level, and the choice of action.

Thus, this paper considers that the liaison between professional judgment and decision is a part-whole relationship. In fact, professional reasoning is considered a 
component of the decision-making process. Explicitly, the relationship between judgment and decision can be abridged according to the following figure:

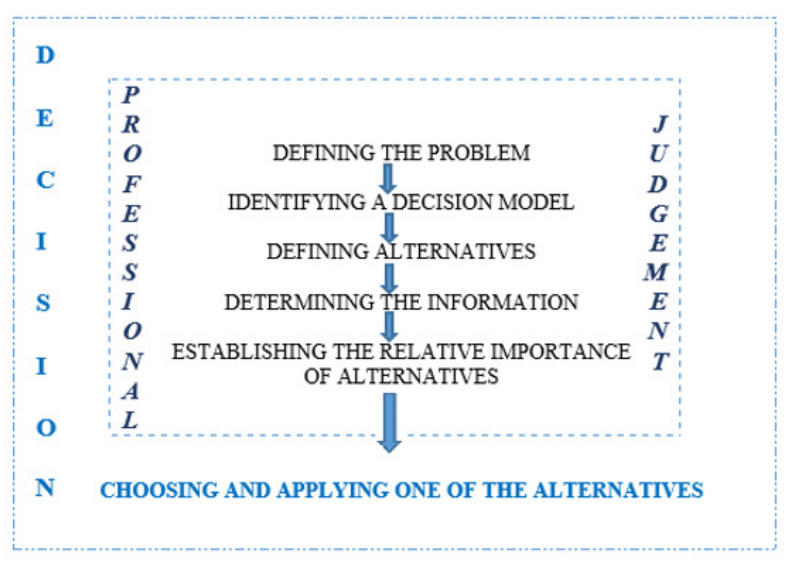

Fig .1: The relationship between decision and professional judgment/reasoning

Source: own projection

As stated by Bonner (1999), there are three basic features from which judgment can be assessed, namely: the professional (who applies the professional reasoning), the task or the activity (for which it is necessary to exercise the reasoning), as well as the environment or the context (which influences the applied reasoning). With the aim of understanding and analysing these three elements, an adequate documentation should be used.

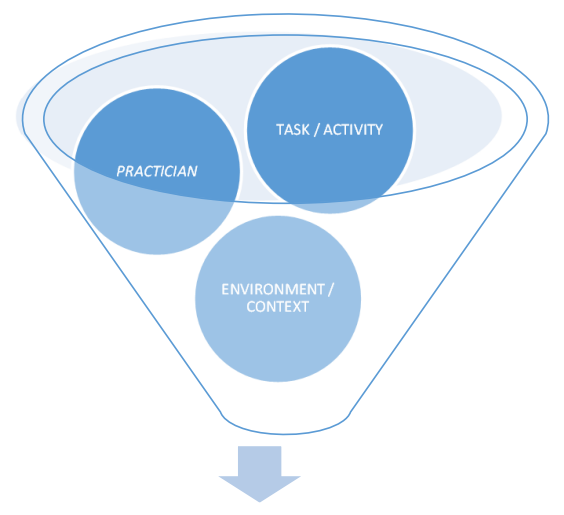

PROFESSIONAL JUDGEMENT

Fig. 2: The elements from the perspective of which the professional judgment can be evaluated

Source: own projection

In this respect, possible deficiencies that may arise from the level of reasoning concerning the responsible professional, refer to the lack of knowledge, experience and abilities possessed by him. The activity itself can also impact the results of the decision-making process, while the contextual factors entail a particularization of the professional judgment on the specific activity.

Professional reasoning can be drilled by people who have not only the necessary knowledge, but also a certain experience, as well as an objective attitude to be able to 
make choices based on facts and settings relevant to the concerned activity. Judgment of the professionals may be different depending on the level of knowledge, experience or skills, but these dissimilarities are not able to advocate whether a reasoning is correct or not. In this study's view, the existence of several alternatives is essential before making a final decision. These ought to be carefully documented, otherwise it will become much more problematic to justify or argue the chosen decision.

Professional reasoning can be perpetually enhanced and developed by participating in dedicated trainings, by expanding knowledge grounded on accumulated experience and through rigorous documentation. Justification of decisions through adequate documentation has the role of increasing the worth and level of public confidence in the exercised reasoning. Making correct and judicious decisions comprises professionals' critical thinking. Smearing reasoning is an insightful and self-correcting process that takes into account knowledge, circumstances, proofs and evidence, methods and a variety of criteria, and appropriate standards.

Next, this paper intends to present the way of exercising professional judgment in the profession of audit or a liberal profession.

\section{Research Methodology}

Most of this paper is dedicated to fundamental research, comprising numerous debates about professional judgment as a fundamental concept, mainly its impact on a financial audit mission performed by an external auditor.

By its nature, this paper is a part of the positivist research trend with extensive interpretative approaches (regarding the current perception on the factors, elements and dimensions of auditors' professional judgment) and with a number of critical elements and many personal opinions, which intertwine harmoniously and give the article a touch of originality and professionalism. In terms of generated information, this research focuses on a qualitative research (most investigated items being of qualitative nature).
The research follows a transverse direction through using observation, comparison and conceptual analysis techniques. Thus, the qualitative research valued the specialist literature by processing it with various methods specific to socio-human sciences, such as document analysis, nonparticipating observation and comparison. The non-participating approach is due to the research field and the current state of knowledge in the field of interest, although comparisons made and opinions and conclusions expressed show certain participating aspects of the research, as well as the relevance of transmitted information.

A future research will be reserved for the applied research, where the cultural differences regarding the psychoprofessional elements will be put face to face in relation to auditors' professional reasoning, taking into consideration samples of auditors from different countries and cultures.

In the opinion of the author, the dynamics of analysing scientific literature is extremely relevant in the analysis of audit quality and audit trends, and consequently for increasing the complexity of tasks and responsibilities attached to financial auditors, the more that we talk about periods of socio-economic or financial crises. The sources used are mostly research papers published in scientific journals in the field of auditing, management and psychology.

\section{Financial Auditor's Profession and Professional Reasoning}

All professions, regardless of their fields, are governed by rules, standards and principles applied in order to carry out the related activities in good conditions. The particular character of the services and beneficiaries' needs to use the services provided with confidence determine the existence of strict technical, ethical and moral rules.

Davis (1992), states that professionals must make competent choices and decisions. Moreover, he argues that "an engineer without an engineering thought, a lawyer without the specific reasoning of a lawyer or any other professional without 
the judgment and the specific thinking that sets him apart from other professionals would be just an incompetent individual who would not be able to practice his profession honestly".

In the author's opinion, professional reasoning is a specific approach to liberal professions. These are legally regulated professions and involve the exercise on the basis of relevant qualifications, certified by legal institutions, registered and recognized by the state. Within these professions, intellectual services including conceptual ones are offered, in an independent and responsible manner as highlighted in the Larousse Dictionary. The work of professionals working in the liberal professions is dedicated to protecting and realizing both public and private interests. Liberal professions bring together professionals from the legal, medical, accounting, technical and other fields, in addition to professionals who work independently, the spirit of initiative and professionalism, as well as the flexibility in action representing the expressions of this liberal way of working. In this respect, the liberal professional is the person whose duty is to render services to his clients independently, and who, within the deontology of his profession, guarantees the respect of professional secrecy. Those professionals have a recognized competence, having the obligation to answer for their actions in the exercise of the profession for which they were empowered. In this respect, another important aspect for those who practice their professions in a liberal manner is that they comply with the moral and professional norms that exceed the minimum legal conditions.

Professional judgment is made on the basis of the "reasonable person principle", so it is unlikely that a decision that contravenes the legislation will be considered correct, this refers to the fact that decisions made by professionals can be rationally understood and used by a person who has minimal knowledge in the field of interest. There are, however, exceptions, such as unforeseen situations that cannot be anticipated and included in the general specifications of the law, when the professional makes decisions according to the problem's particularities, without violating legal provisions.

In this regard, this study emphasizes that, in the accounting profession, the application of professional judgment is a complex activity, which combines the aspects of reality with the economic, technical and ethical elements of the profession. Accounting can be defined as a language of communication, "the language of business", because through it, entities communicate to different categories of users' information which they need, and thus, in the same way that different nations of the world have shaped their own language, over time, each country has developed its own "accounting language" and its own standards in the field, as shown by Wilkins (2010). Communication of information with the help of "accounting language" is a process based on the professional judgment of the producers of financial-accounting information (the accountants), but also of those who make sure that they correspond qualitatively (the auditors).

The importance of professional standards in the field of accounting is a major one. The diversity of these standards (including ethical principles) and the fact that they are constantly changing, make auditing a complex and often difficult profession. The professional standards in the field do not have the power of universal regulations, but they have the role of providing a general framework of action - here intervening the role of the professional of adapting the general framework of action to completely specific situations (through professional reasoning!).

Xiling-Dai (2010) states that professional judgement is "the process by which accounting professionals consider a complex of elements such as: the current and expected financial environment, the characteristics of the management of the client-entity, the accounting methods, the ability of logical analysis and the professional experience". The exercise of professional reasoning involves judging and selecting the principles and methods, and scheduling the daily accounting activities in order to prepare the financial 
reports. Since there are financial factors and indicators that cannot be accurately determined, in practice, accounting professionals must make forecasts and estimates regarding their value. "Due to the uncertain economic activity, accounting professionals must reasonably forecast and deduce accounting information. The accuracy of the confirmations depends on the ability of the accountant to exercise his professional reasoning".

The author also reminds that the accounting and auditing standards sometimes contain expressions such as: "probable", "reasonable assurance", "accurate representation" or other general expressions, giving professionals the freedom to decide based on their own judgment (as Chand \& White (2006) and Patel et al. (2002) outline). In other words, the imprecision of professional standards causes accounting and auditing professionals to make decisions and formulate opinions through the prism of professional judgment.

A large part of the professionals supports the prerequisite to merge the way of exercising professional reasoning. The diversity of solutions shows that, under the meaning of the concept, a variety of masking of the less legal aspects, with which they operate, can be hidden (through accounting manipulation and affecting the decision-making process). After studying the specialized literature, it was found that the professional reasoning is applied mainly in countries with an Anglo-Saxon accounting system -a customs-based and poorly regulated system, in which professional judgment acquires a key role.

A significant step towards unifying the way of practicing the accounting and auditing profession was the immersion of the four major international assurance companies, namely the Big 4 group, the application of International Auditing Standards and International Financial Reporting Standards being considered a method of unifying and standardizing the activity of auditors and accountants (Deloitte (2008), KPMG (2008), PWC (2009) and Ernst \& Young (2009)). The fact that these corporations operate internationally has allowed them to carry out studies which resulted in the fact that the professional reasoning is influenced by a large number of factors, an aspect that increases the complexity of the process. The quality of the services in the field of accounting and auditing is greatly influenced by the professional reasoning. According to Roy (2011), the "culminating point" of the activity is the moment when professionals try to apply the general standards on an infinite variety of complex situations that appear in the economic environment, as in a sensitive socioeconomic context, characterized by a financial crisis.

Looking at things from the opposite perspective, the author can specify that without the flexibility offered by applying professional reasoning, the complex system of accounting procedures, professional standards or rules would be totally nonfunctional. The exercise of professional reasoning - especially in a turbulent economic environment - can lead to correct decisions or, conversely, decisions that produce negative effects.

The difference between a correct and an incorrect reasoning is often problematic to observe, as this border can be quite abstruse. 
Table 1: The factors of influence of an erroneous reasoning vs those of a correct reasoning

\begin{tabular}{|c|c|}
\hline Causes of an ERRONEOUS REASONING & Conditions of a CORRECT REASONING \\
\hline $\begin{array}{l}\text { - not assimilating all data in the decision- } \\
\text { making process; } \\
\text { - paying attention to details and neglecting } \\
\text { important general elements; } \\
\text { - excluding the opposition and conflicts } \\
\text { between different solutions (one decision } \\
\text { may be contrary to another); } \\
\text { - exercising competent behaviour in the } \\
\text { essential phases of the process, but making } \\
\text { erroneous decisions in the less important } \\
\text { aspects; } \\
\text { - making decisions based on current } \\
\text { evidence and overlooking earlier or } \\
\text { previous info; } \\
\text { - omitting less obvious and inconsequential } \\
\text { elements, but which, combined with } \\
\text { others, can distort the meaning of the } \\
\text { decisions taken. }\end{array}$ & $\begin{array}{l}\text { - distinguishing the key features of the issue } \\
\text { in a most complex and comprehensive way; } \\
\text { - conducting the activity beyond the limits } \\
\text { imposed by regulations and rules; } \\
\text { - making less radical decisions, which can } \\
\text { then be subject to alterations; } \\
\text { - unwillingness to make any decision in } \\
\text { circumstances of lack of justification. }\end{array}$ \\
\hline
\end{tabular}

Source: own projection, after Mamede et al. (2008)

From what is presented above, it can be concluded that professional reasoning is a common process that is based on elements

such as: knowledge in the field, experience, skills and adequate documentation.

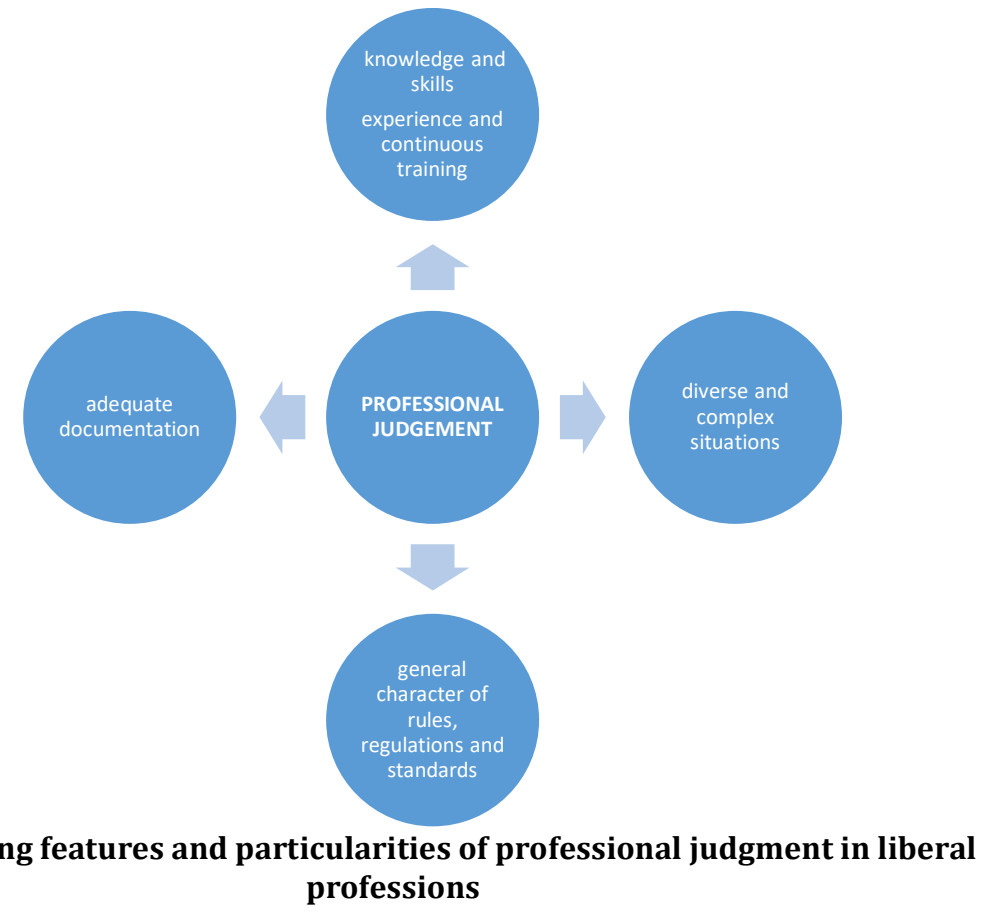

Source: own projection, after Şpan (2013) 
Trotman (2006) showed concerns linked to the fact that in most professions, the struggle of exercising professional judgment is well-known and made arguments in this regard, discussing how to apply the judgment in the medical, legal, security, sales and marketing, or accounting professions. Thus, reasoning errors can occur in any of these areas, without a category of professionals being exempted from responsibilities or asked to be more accountable than another category of professionals.

In this context, it is important to mention that although financial auditors, like professionals, carry out missions at the highest standards, they may not be able to identify all frauds or errors, especially when the entity's management makes every effort to cover these actions.

\section{Psychological Factors Influencing the Exercise of Auditors' Professional Reasoning}

Elements of professional nature involved in the decision-making process from the perspective of the Code of Ethics of the accounting professional

The professional qualities of the specialists are generally derived from the requirements formulated in the Code of Ethics for each particular field. These are stated in the form of fundamental ethical principles. Ethics, according to Falise \& Regnier (1992), is "a personal dynamism, a global and creative concern to give meanings to our actions, to choose values and priorities and to comply with our practice". Ethics can be expressed through principles, rules and practices. Respecting ethics, in practice, can be difficult to achieve, as the professional may choose to act like other practitioners or act differently than how the majority are used to. Making a decision or adopting an ethical behaviour may require courage and strength of character.

Each of the liberal professions; the legal one, the medical one and the accounting profession, is based on a deontological code that governs the behaviour of the professionals in carrying out the activities, as well as the ethical responsibilities that they have in the relationships with the clients, their colleagues and the professional bodies of which they belong.

The existence of the same deontological principles in the professions mentioned above demonstrates the similarity between them and the common foundation in the exercise of professional reasoning. The deontological norms are intended to guarantee, by their acceptance, the good fulfilment by any professional of his mission for the functioning of any human society. If the one aspect mentioned above is taken into account, according to which reasoning defines a profession, there could be an affirmation that ethical principles are essential elements for the application of an adequate reasoning. In other words, an important aspect of reasoning is represented by the fundamental ethical principles of the profession.

Thus, in order to outline the profile of the auditing specialist who exercises professional judgment, the Code of Ethics of the accounting professionals issued by the International Federation of Accountants (IFAC) contains common principles (which form the ethical basis of the professional reasoning); principles that every accounting professional is due to follow: independence, confidentiality, integrity, competence and professional behaviour.

Although the interest towards the client, as well as the relations with the other members of the profession and with the collaborators (specific to the ethical codes of the legal and medical profession) are not explicitly found with the same frequency in the ethical code of the accounting profession, it can be considered that the accounting professionals fulfil them as well, as they are complementary to other ethical principles. Thus, conducting the activity focusing on integrity implies an objective attitude. The responsibility can be associated with pursuing the interest towards the public. The professional behaviour includes, at the same time, respecting the reputation and integrity of relationships with colleagues and collaborators within the profession.

However, it was found that responsibility, as an ethical principle, is not explicitly 
stated. Nevertheless, responsibility could be considered subsistent and implicitly included in the principle of "professional behaviour". Therefore, responsibility can be considered as an omnipresent principle.

In the author's opinion, deprived of sound professional knowledge, professional reasoning is nonsense. In this situation, its etymology itself is devoid of content and the basic condition for its exercise being professionalism itself. Nonetheless, in numerous situations, the idiom "professional judgment" covers states that are difficult to explain, coming to provide a generic answer when arguments, and sometimes logic, are missing.

\section{Psychological factors from the exercise of Professional Reasoning}

Beside meeting professional standards and ethical principles, the existence of psychological traits, which will give the professional auditor the opportunity to have sufficient confidence in his abilities and competence, will increase the quality of the offered services. Whether it is about experts (with more than 10 years of experience) or novices (with less than 2 years of experience), auditors express different attitudes, reasoning and judgments.

Some practitioners are receptive to change or novelty, whereas others scarcely accept innovation elements that entail a deviation from the pattern outlined throughout their career. Regarding their activity, some try to approach the issues diligently, concentrating on methodical approaches of solving them, while others incline to show a superficial, disorganised or slightly confused attitude.

Amid the specialists, there are two approaches regarding identifying solutions. The first of these options, expressed by Facione et al. (1997), targets analysing the complexity of the problem and categorising multiple solutions, while the second approach is a dualistic and extreme one; of the "good or bad", "right or wrong" and "true or false" type.

Libby \& Thorne (2000) conducted a research on the key virtues that professionals, especially those in the accounting field, should possess so as to carry out professional activities andexercise an adequate reasoning. They started from the study steered by Pincoffs (1986), in which the qualities necessary for carrying out such a process were divided into two categories: instrumental and non-instrumental. Non-instrumental virtues; mainly moral ones, are the auditor's predisposition to formulate an inherently professional judgment and in accordance with an ethical standard. Instrumental virtues, on the other hand, embody the indispensable character traits and the behavioural features.

The table below presents the structure of these qualities exposed by Pincoffs (1986) and supplemented by Libby \& Thorne (2000).

Table 2: Qualities-virtues necessary for a professional accountant in the vision of Pincoffs (1986) and Libby \& Thorne (2000)

\begin{tabular}{|c|c|c|c|}
\hline \multicolumn{2}{|c|}{ Instrumental Qualities } & \multicolumn{2}{|c|}{ Non-Instrumental Qualities } \\
\hline \multicolumn{2}{|c|}{$\begin{array}{l}=\text { qualities that ensure the proper conduct of } \\
\text { professional reasoning }\end{array}$} & \multicolumn{2}{|c|}{$\begin{array}{l}=\text { necessary for a professional judgment } \\
\text { according to the generally accepted principles of } \\
\text { the profession }\end{array}$} \\
\hline Pincoffs (1986) & $\begin{array}{c}\text { Libby \& Thorne } \\
(2000)\end{array}$ & Pincoffs (1986) & $\begin{array}{c}\text { Libby \& Thorne } \\
(2000)\end{array}$ \\
\hline 1. Persistence & 1. Diligence & 1. Reliability & 1. Skepticism \\
\hline 2. Attention & $\begin{array}{l}\text { 2. Discipline } \\
\text { in activity }\end{array}$ & 2. Dependence & 2. Objectivity \\
\hline 3. Prudence & $\begin{array}{l}\text { 3. Lack of } \\
\text { pressure }\end{array}$ & 3. Safety & 3. Independence \\
\hline 4. Ability & $\begin{array}{l}\text { 4. Deepening } \\
\text { decisions }\end{array}$ & 4. Honesty & 4. Integrity \\
\hline 5. Stability & 5. Stability in & 5. Sincerity & \\
\hline
\end{tabular}




\begin{tabular}{|l|l|l|l|}
\hline 6. Courage & decisions & & \\
\hline
\end{tabular}

Source: own projection

Richard\& Elder (2002) draw attention to a typology of thinking that professionals may possess, and that regulates the focus on certain facets in the decision-making process leading to dissimilar results. They sustain the existence of "a creative thinking manifested by the curiosity and the openness to the professional's novelty, a reflexive, detail-oriented thinking or a critical thinking manifested by a strategic behaviour and a skeptical attitude".

Stockett (2006) indicates other elements that should be analysed in the attitude and behaviour of those exercising professional reasoning. He emphasized the importance that the character of the professional has in forming of certain judgments. An attitude characterized by courage, empathy, justice, persistence, ambition or trust is considered to be beneficial for the successful completion of a decision-making process. In Stockett's opinion, intellect is another factor that competes with the foundation of professional reasoning, which can be manifested through accuracy, diversity, openness to novelty and change, as well as receptivity or problem solving.

Professional intelligence and the ability to anticipate and react in different situations are essential for effective results. Among the evidences regarding the professional intelligence highlighted by Hansen (2001) are: curiosity, openness to novelty, decision-making power, ability to systematize, ability to deliberate, strategic attitude, diligence, impartiality and deliberation. "Intellectual performance is not just an exercise of skills. It is more of a disposition of our actions in the field where we activate skills transposed into deeds. The provisions refer not only to what we can achieve, but also to what we actually accomplish or tend to do, referring to the gap that often exists between our abilities and actions" (Ritchhart (2002)).

Specialization improves performance in spawning hypotheses and applying further investigations, which will, according to Wright \& Wright (1997), lead to higher quality results.

Another study in which a list of the most important attributes that a professional, and implicitly a financial auditor, has to possess for successfully applying professional reasoning is presented is the study by Abdolmohammadi \& Shanteau (1992). Unlike Libby \& Thorne (2000) or Pincoffs (1986), they include, in a single category, both the characteristics of the professional and the ethical principles to which he must adhere, as shown in the summary table below.

Table 3: Attributes required by the professional accountant in the vision of Abdolmohammadi \& Shanteau (1992)

\begin{tabular}{|c|}
\hline Attributes \\
\hline $\begin{array}{c}\text { = necessary for exercising professional reasoning } \\
\text { Abdolmohammadi \& Shanteau (1992) }\end{array}$ \\
\hline 1. Knowledge of what is significant \\
\hline 2. Responsibility \\
\hline 3. Updated knowledge \\
\hline 4. Adaptability and flexibility \\
\hline 5. Receptivity / Intuition \\
\hline 6. Experience \\
\hline 7. Determination \\
\hline 8. Self-confidence \\
\hline 9. Stress resistance \\
\hline 10. The ability to communicate \\
\hline 11. Creativity \\
\hline 12. Curiosity \\
\hline
\end{tabular}


13. Simplifying problems

14. Recognition of exceptions

15. Selecting problems

Source: own projection

Through an overview of the information presented above, it can be considered that in addition to the theoretical knowledge related to a professional training, the financial auditor, as an accounting professional, needs to have sufficient experience, communication and teamwork skills, the ability to distinguish the important and relevant elements for the fulfilment of his duties and responsibility towards his tasks.

The manifestation of a skeptical and objective attitude contributes to the exercise of control over the decisions taken and the results obtained. Also, the combination of professional qualities and competences with psychological ones aims to offer correct, clear and convincing solutions for the beneficiaries of the services offered, and consequently for the economic entities audited by them.

The objective of the study on the specialized literature was knowing and highlighting the importance of this topic among the researchers, on one hand, and on the other hand, the identification of the elements and factors that can be associated with the financial auditors' professional reasoning and their decision-making process. Therefore, two basic questions are outlined:

- Q1: How important is the professional judgment and the decision-making process when carrying out the audit missions, as well as what impact does these have on the financial auditor's responsibility and liability?

- Q2: What are the elements that can influence the way of exercising professional judgment?

- Q1: The answer to the first question is found in a piece of information provided in the research conducted by Trotman et al. (2011) according to which, during the period 1960-2010, approximately 5745 studies were elaborated on the topic of professional judgment and decision-making process. This demonstrates the major interest of researchers, practitioners and even professional bodies to know so much about how to exercise the reasoning, given that it is a frequently used process in the financial-accounting activity. In Trotman's opinion, professional reasoning is also "exercised by: auditors - to the extent that the entire audit process is influenced by the auditors' judgment, as mentioned in the International Auditing Standards; accountants - who apply the professional reasoning regarding the information processed, the necessary accounting treatments, as well as the forecasts they carry out; users of accounting information (investors, analysts, bankers, etc.) - who make judgments about future earnings and cash flows, decisions to invest or not in the respective business, decision whether to grant loans or not, etc.; and managers who exercise professional reasoning in planning activities, evaluating performance or allocating resources".

Thus, it was found that professional reasoning is of major importance due to the fact that it is used in most professions including the accounting profession (as highlighted above), as well as by all participants in carrying out its activities.

- Q2: In order to answer the second question, it is necessary to carry out another analysis of the specialized literature. Considering that the professional reasoning is a process with implications in all the decisions of an assurance mission, it can be deduced that it is influenced by a complex set of elements both inside the entity and in its external environment.

Audit research has discussed issues related to evaluating the quality of auditors' judgment, describing how decisions are 
made, establishing the elements that contribute to professional judgment, developing and testing theories focused on cognitive processes, and identifying methods to improve the way auditors exercise professional reasoning (Libby et al. (1990), Trotman (1996), Libby \&Luft (1993), etc.).

Five decades ago, the socio-economic environment was simpler than it is now, and accounting professionals were faced with operations and transactions without too many implications for the management or verification of which no complex reasoning was necessary. However, over time, , the diversification of the offer in response to the various demands of the public has led to the emergence of much more difficult situations. Solving these situations required a continuous preparation and a good capacity for reasoning.

This aspect is reflected in the specialty literature. Specifically, studies from the 1960s have shown that the exercise of "good" reasoning is limited to the knowledge and understanding of accounting information, as well as the treatments applied in its processing (Bruns (1965-1966), Dyckman (1964) and Jensen (1966)). However, over the next ten years, new elements that were considered important in substantiating judgments and decision-making will gradually emerge. These include the characteristics of the client-entity environment, the consensus between auditors regarding the different decisions within the audit mission (Ashton (1974) and Joyce (1976)), accuracy (Weber (1978)), time stability on how to exercise the professional judgment, as well as the importance of the auditors' individual features in substantiating their own judgments (Trotman (1996)).

Libby \&Luft (1993) carried out an analysis of researches on the topic of professional reasoning, their study, surprising the emergence of new trends in the research already carried out, changes due to the increase of the economic and social complexity. The study proposes a model of performance review and evaluation, considering that experience and the ability to contribute to knowledge development directly affect the level of performance. Other studies that followed the same research direction are those conducted by Wright (1982), Kaplan \& Reckers (1985) or Luckett \& Hirst (1989).

Therefore, it is concluded that, if during the period 1960-1980, the analysed factors concerned were, in particular, the accounting information and its processing, after 1980, the research in the field of professional judgment had "Human Information Processing" as a central point, as Trotman et al. (2011) point out. The studies conducted after 1980 have followed the development of experimental research regarding the role of knowledge, motivation and environment on the performance of auditors. The ideas outlined in all these papers refer to the role of knowledge in increasing the performance of auditors, as well as the need to outline specific tasks in carrying out audit missions.

Also during the 80s, interesting studies began to take shape, focusing on the analysis of the professional reasoning in determining the materiality - in particular the study of Messier (1983)), on the behaviour of the auditors regarding the achievement of the forecasts-the study of Danos\&Imhoff (1983), as well as on the role of the internal audit system in substantiating professional reasoning-the studies of Abdel-Kalik et al. (1983) and Schneider (1984).

It is noted that the specialized literature brings to the fore a possible interference between psychological factors of a cognitive-behavioural nature and the way of exercising reasoning in decision making. Memory, motivation, disposition and other similar factors are a part of the category of elements capable of creating differences in the decision-making process (Solomon \& Shields (1995), Nelson et al (2005), etc.). 


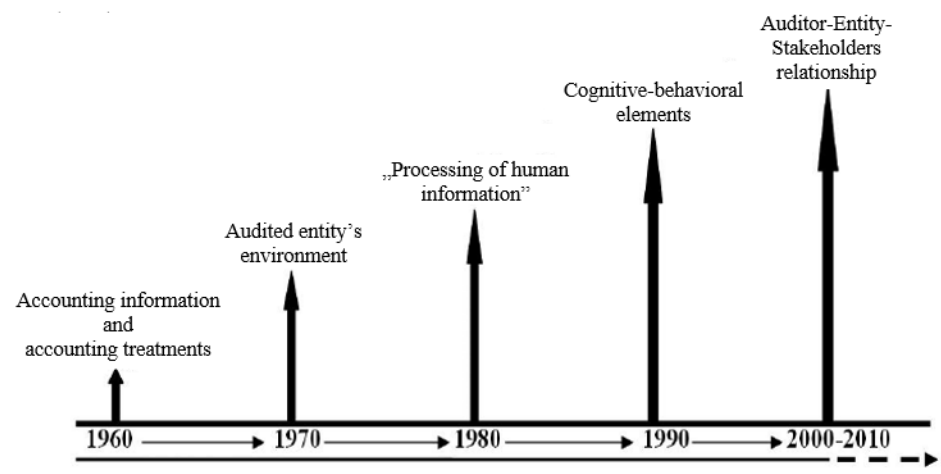

Fig. 4: The evolution of the elements associated with professional judgment in audit

Source: own projection, after Şpan (2013)

Therefore, analysing the way in which the elements associated with the professional judgment in audit have evolved (see the figure above), the specialized studies debuted around the 1960s will be observed, considering the accounting information and the accounting treatments, while in 1970, studies focused on the audited entity's environment. The 1980s brought about a change in the optics of the researchers. Also, they tried to sketch the professional characteristics and abilities of the person exercising the professional reasoning in terms of "Human Information Processing ", resulting in, in 1990, the cognitive-behavioural elements of the auditor which attracted the attention and the interest of the researchers.

The latest studies in the field, regarding the central element that revolves around the professional reasoning of the auditors, emphasize the investigation of elements associated with the relationship between auditors and entity, entity and beneficiaries or a relationship between the three parties: auditor - client (audited entity) - users.

\section{Conclusions}

The need for professional reasoning is related to the very appearing and evolution of external audit, the professional rules in auditing being, in their quasi-totality, almost all of Anglo-Saxon inspiration, the need for a professional judgment in carrying out the audit missions is essential.

The professional reasoning in audit means, in a broad sense, the application of relevant knowledge and experience, in the context of audit and accounting standards, as well as the ethical code, in order to make the correct decision from a set of existing alternatives.

From all of the presented above, it can be concludeded that the decision-making process can be described as an activity through which professional reasoning, based on experience and knowledge (including the ability to identify the limits of knowledge), is applied objectively, prudently and completely, as well as by ascertaining and recognizing the responsibility towards those affected by the consequences of the issued judgment.

In the author's opinion, regarding the content of the professional standards in the field of auditing, there are at least three main reasons that determine the professionals to make use of the professional judgement in order to obtain a reasonable assurance during an audit mission.

Thus, the audit standards' characteristics that require the application of a professional judgment are the following:

- general character (in the elaboration of ISA, the legislators cannot take into account all the situations that may appear in practice, which means that the auditors will adapt to the circumstances encountered and will apply their own judgment. From this point of view, being able to consider that the professional norms are useful for protecting the auditors' activity, but cannot substitute the place of professional reasoning and the results obtained with its help); 
- interpretable character the professional norms, both in audit and accounting, are relative in the formulations they contain - for example, encountering expressions such as "it is desirable", "it may be necessary", "to the extent that it is possible", "reasonable assurance", "significant", etc. -do not indicate an obvious direction in the activity, leaving the possibility of choosing the mode of operation. On a different note, a norm can offer alternatives to follow; sometimes a basic existing treatment or an alternative one. The professional's role is to choose, based on professional reasoning, the optimal option. Another important aspect is that the rules are not always sufficient (e.g. treatment of errors, accounting estimates or change of methods and accounting policies), relying on the principle of relative importance, which is strongly particularized by the reasoning of the accounting professional;

- complex and unstable nature of the environment (over time, due to the socio-economic changes, the legislators were forced to adapt the professional standards to the new market conditions, the standards undergo a series of changes designed to meet the auditors' demands and contribute to the growth quality of audit missions).

In the author's opinion, the audit judgment cannot be eliminated by elaborating detailed rules or procedures; on the contrary, it requires a deep understanding of accounting and auditing theories, which must be specific enough to provide a solid basis in the decision-making process. However, it is worth noting that professional audit reasoning cannot be performed outside the norms and that the exercise of reasoning takes place within a hierarchical framework that includes established objectives, qualitative characteristics, principles and existing norms, without ultimately excluding a certain dose of compromise.

A professional auditor is required to maintain the highest level of training and keep up with the new research and scientific developments in the field. Therefore, the professional reasoning will be constantly subjected to an improvement process that can be warranted through continuous information and training. Experience denotes not only seniority in the field of activity, but also refers to the way in which the professional has coped with previous situations, contributing to the enlargement of his abilities, competence and knowledge. Expertise can be demarcated in terms of knowledge, experience, decision-making process and quality in the professional's reasoning. Experience and training create knowledge, while this, together with the skills, support the quality of the professional judgment and of the services offered.

In any case, the auditor is obliged to adopt a certain level of uncertainty or risk that arises in carrying out the activities he commences. Even if he has sufficient knowledge of his client, reasoning, by maintaining a certain dose of skepticism, is beneficial, as situations may have been primarily concealed or presented in a way other than their reality. A skeptical reasoning recognizes the possibility of false information or relevant, but unidentified, information, as well as other probable faults of one's judgment, given that any professional is prone to errors and mistakes.

\section{References}

1. Abdolmohammadi, M. J., Shanteau, J. (1992). Personal Attributes of Expert Auditors. Organizational Behavior and Human Decision Processes, 53 (11): 158-172.

2. Ashton, R. H. (1974). An Experimental Study of Internal Control Judgments. Journal of Accounting Research, 12: 143-157.

3. Bamber, E.M., (1983). Expert Judgment in the Audit Team: A Source Reliability Approach. Journal of Accounting Research, 21(2): 396-412.

4. Bonner, S.E. (1999). Judgment and Decision-Making Research in Accounting, Accounting Horizons, 13(4): 385-398. 
5. Bruns Jr., W.J. (1965). Inventory Valuation and Management Decisions. The Accounting Review, 40: 345-357.

6. Bruns Jr., W.J. (1966). The Accounting Period Concept and its Effect on Management Decisions. Journal of Accounting Research, 4: 1-14.

7. Butler, S.A., (1985). Application of a Decision Aid in the Judgmental Evaluation of Substantive Test of Details Samples. Journal of Accounting Research, Autumn, 23(2): 513-526.

8. Chand, P., White, M. (2006). The Influence of Culture on Judgments of Accountants in Fiji, Australian Accounting Review, 16 (38): 82-88.

9. Danos, P., Imhoff, E.A., (1983), Factors Affecting Auditors' Evaluations of Forecasts.Journal of Accounting Research, 21(2): 473-494.

10. Davis, M. (1992). Professional Judgment. Perspective on the Professions, 11(2), Chicago.

11. Deliu, D. (2013). The Responisbilities and Limited Liability of the Financial Auditor in a Sensitive Socio-Economic Context. PhD thesis, West University of Timişoara, Timişoara.

12. Dottin, E.S. (2009). Dispositions as Habits of Mind: Making Professional Conduct More Intelligent. University Press of America.

13. Dyckman, T. (1964). The Effects of Alternative Accounting Techniques on Certain Management Decisions. Journal of Accounting Research, 2(1): 91-107.

14. Facione, A.P., Facione, C.N., Giancarlo, A.F.C. (1997). Professional Judgment and the Disposition Toward Critical Thinking. California Academic Press: 117.

15. Falise, M., Regnier, J. (1992). Reperespor un etiquedentreprise. Centre D`EtiqueContemporane.

16. Jensen, R.E. (1966). An Experimental Design for Study of Effects of Accounting Variations in DecisionMaking. Journal of Accounting Research, 4: 224-238.
17. Joyce, E.J. (1976). Expert Judgment in Audit Program Planning. Journal of Accounting Research. 14: 29-60.

18. Kaplan, S.E., Reckers, P.M.J (1985). An Empirical Examination of Auditors' Initial Planning Process. Auditing: A Journal of Practice and Theory, 4(1): 119.

19. Libby, R., Luft, J. (1993). Determinants of Judgment Performance in Accounting Settings: Ability, Knowledge, Motivation and Enviornment.Accounting, Organization and Society, 18:425-450.

20. Libby, R., Kinney Jr., W.R. (2000), Does Mandated Audit Communication Reduce Opportunistic Corrections to Manage Earnings to Forecasts?The Accounting Review, 75(4): 383-404.

21. Libby, R., Nelson, M.W., Hunton, J.E. (2006).Recognition v. Disclosure, Auditor Tolerance for Misstatement and the Reliability of StockCompensation and Lease Information.Journal of Accounting Research, 44(3): 533-557.

22. Libby, T., Thorne, L. (2000). Auditors' Virtue: A Qualitative Analysis and Categorization. Business Ethics Quarterly, 14(3): 479-498.

23. Luckett, P.F., Hirst, M.K. (1989). The Impact of Feedback on Inter-Rater Agreement and Self-Insight in Performance Evaluation Decisions. Accounting, Organizations and Society, 14: 379- 387.

24. Mamede, S., Schmidt, H. (2008). Effects of Reflective Practice on the Accuracy of Medical Diagnosis. Medical Education, 42: 468-475..

25. Messier Jr., W.F. (1983). The Effect of Experience and Firm Type of Materiality / Disclosure Judgments. Journal of Accounting Research, 21(2): 611-618

26. Nelson, MW., Smith, S. D. Palmrose, ZV. (2005). The Effect of Quantitative Materiality Approach on Auditors' Adjustments Decisions. The Accounting Review, 80(3): 897-920. 
27. Patel, C., Harrison, G.L., McKinnon, J.L. (2002).Cultural Influences on Judgments of Professional Accountants in Auditor-Client Conflict Resolution.Journal of International Financial Management and Accounting, 13(1): 1-31.

28. Perez, S.M., (2001). Consideracionespsicologicas de la formacion del juicio del auditor: la importanciarelativaen la planificacion de la auditoria, PhD thesis, SevillaUniveristy.

29. Pincoffs, E. (1986). Quandaries and Virtues. Lawrence, KS: University Press of Kansas.

30. Popa, I.E., Şpan, G.A. (2016). The Role of the Professional Judgment and Decision-Making Process in the Relation External Audit - Corporate Governance. in Corporate Governance in Knowledge-Based Society, WSEAS Press, pp. 229-247.

31. Richard, P., Elder L. (2002). Critical Thinking: Tools for Taking Charge of Your Professional and Personal Life. Pearson Education, Ed. Financial Times Prentice Hall, New Jersey.

32. Ritchhart, R. (2002). Intellectual Character: What It Is, Why It Matters, and How to Get It. San Francisco: Jossey-Bass.

33. Roy, E. P. (2011). Research Report on Professional Judgment Matters, White paper.

34. Schiller, S. (2013). Heuristics or Experience-Based Techniques for Making Accounting Judgments and Learning.Problems and Perspectives in Management, 11(3).

35. Schneider, A. (1984). Modeling External Auditors' Evaluations of Internal Auditing. Journal of Accounting Research, 22(2): 657-678.

36. Solomon, I., Shields, M.D. (1995). Judgment and Decision Research in Auditing, in: Ashton, R.H., Ashton, A.H., eds., Judgment and Decision-Making Research in Accounting and Auditing (Cambridge University Press, New York): 137-175.
37. Span, G.A. (2012). Foundation of the Prrofessional Judgment in Statutory Audit. PhD thesis, Babeş-Bolyai University, ClujNapoca.

38. Trotman, K.T., (1996), The Review Process and the Accuracy of Auditor Judgments.Journal of Accounting Research, 23(2): 740-752

39. Trotman, K.T. (2005). Discussion of Judgment and Decision Making Research in Auditing: A Task, Person, and Interpersonal Interaction Perspective. Auditing: A Journal of Practice \&Theory: 73-87.

40. Trotman, K.T. (2006). Professional Judgment: Are Auditors Being Held to a Higher Standard than Other Professionals?Center for Accounting and Assurance Services Research, University of New South Wales.

41. Trotman, K.T. (2011). A Different Personal Perspective through the Behavioral Accounting Literature. Behavioral Research in Accounting, 23(1): 203-208.

42. Trotman, K.T., Tan, H.C., Ang, N. (2011). Fifty-Year Overview of Judgment and Decision-Making Research in Accounting.Accounting and Finance, 51: 278-360.

43. Weber, R. (1978). Auditor DecisionMaking on Overall System Reliability: Accuracy, Consensus and the Usefulness of a Simulation Decision Aid. Journal of Accounting Research, 16 (2): 368-388.

44. Wilkins M. A. (2010). An Experimental Analysis of Accounting Judgments between US GAAP and IFRS Accountants, 19th EDAMBA Summer Academy Soreze, France.

45. Wright, A., Wright, S. (1997). An Examination of Factors Affecting the Decision to Waive Audit Adjustments. Journal of Accounting, Auditing \& Finance, 12(1): 15-36.

46. Wright, A. (1982). An Investigation of the Engagement Evaluation Process for Staff Auditors. Journal of Accounting Research, 20: 227-239. 
47. Xiling-Dai, D. (2010). Study on Relative Problems about the Accountant Professional Judgment Ability,
International Journal of Economics and

Finance, 2(3). 